\title{
HOUSEHOLD ECOLOGICAL PREFERENCES AND RENEWABLE ENERGY SPENDING
}

\section{Maciej Malaczewski*}

\begin{abstract}
In this paper, we propose a model that demonstrates the influence of household ecological preferences on their acceptance of spending on renewable energy. The model discusses the production of energy from both non-renewable and renewable sources, the quality of the natural environment, pollution emissions, and utility maximization. If households choose to reduce pollutant emissions, they should reduce their levels of consumption. The main aspect that distinguishes the proposed model is the assumption of complementarity between physical capital and energy. This complementarity exists due to the fact that non-renewable natural resources are the main energy source throughout the world. The presented model is solved and analysed in detail. Our analysis of the model leads to the conclusion that maximizing the utility share of the total production spent on renewable energy generation depends on the relation of both preference parameters, not on each individual preference parameter. Since the presented model helps to explain several economic mechanisms, it may become incorporated into a larger model.
\end{abstract}

Keywords: ecological preferences, complementarity between natural resources and capital, energy, natural resource use, pollution

JEL Classification: O44, Q32, Q43

\section{Introduction}

The topic of transition to renewable energy sources has been discussed in literature for several years. Some of the most important works in this field are Tahvonen and Salo (2001), Amigues et al. (2004), Di Vita (2006), Burke (2010), Mosi (2012), Maeda and Nagaya (2012), but of course, there are many others. At present, energy is produced mainly from non-renewable sources (according to IEA data, non-renewable sources comprise approximately $81 \%$ of the total energy production in the world). Since non-renewable natural resources are sooner or later going to be depleted (see Lin et al., 2009), it is necessary to consider a transition to renewable energy sources, such as solar, wind, hydropower and others. Some countries are already able to fully satisfy their energy demands using renewable sources; however, these countries are usually small economies, without heavy industry, with convenient geographic location (such as Costa Rica). Nevertheless, all countries will switch to renewable energy sources eventually.

* $\quad$ Maciej Malaczewski, Department of Econometrics, University of Lodz, Lodz, Poland (mmalaczewski@uni.lodz.pl).

The author would like to thank the participants of the annual mathematical economics conference in Poznan for their many valuable comments. Special thanks to my dear wife for her endless support. The usual disclaimer applies. 
The question that dominates the literature on the transition to renewable energy is the question of when and how to do so optimally (Tahvonen and Salo, 2001; Amigues et al., 2004; Di Vita, 2006). In this type of studies, economic efficiency is usually the main issue of interest. The process of switching to renewable resources, however, is not only about economic efficiency. to ensure that it happens, a certain share of the economy's income should be spent on the creation of an infrastructure that will allow the production and distribution of this type of energy. Since these types of investments are underway over a long period of time, it is necessary for the government to ensure public support, as this will allow the investment to be made in the end, regardless of the changing situation. This concept, however, is closely related to household preferences.

According to economic theory, households maximize their utility subject to budget restriction. The utility flows from several sources, of which the most important is the level of consumption (this is the standard assumption in the growth theory, see Barro and Sala-i-Martin, 2003; Acemoglu, 2009). Another important aspect in the analysis of the transition to renewable energy sources is the state of the surrounding environment or, equivalently, the amount of emitted pollutants (Grimaud and Rouge, 2003, 2005, 2008; Schou, 2002; Greiner, 2005; Xepapadeas, 2005; Pautrel, 2008, 2009). A certain level of interchangeability exists between these two factors: if households choose either to reduce the pollutant emissions or to improve the quality of the environment, they should reduce their levels of consumption, as some spending will be necessary. The actual form of this interchange depends on how strongly households prefer consumption over environmental cleanliness, or vice versa.

In existing models in the literature, the substitution (most commonly in the CobbDouglas production function) between capital and natural resources is usually assumed (Dasgupta and Heal, 1974; Solow, 1974; Stiglitz, 1974; Scholz and Ziemes, 1999; Grimaud and Rouge, 2008, 2014; da Silva, 2008; Pittel and Bretschger, 2010; Neustroev, 2013). Such an approach, although it is the most common, carries with it counterfactual consequences most often no exhaustion of natural resources occurs in finite time, and existing resources last in some amount until infinity, only decreasing exponentially in time. Despite a rapid decrease, the studies have shown that the rate of economic growth is positive and constant in time, even though the entire economy is powered by only a few particles of non-renewable natural resources such as oil or coal. Rarely, the mentioned substitution is of limited type, CES type, or is dependent on time, technical progress, etc. (Georgescu-Roegen, 1979; Constanza and Daly, 1992; Smulders and de Nooij, 2003; van Zon and Yetkiner, 2003; Stuermer and Schwerhoff, 2013). Models exhibiting complementarity between natural resources or energy and physical capital (Stern and Cleveland, 2004; Costantini and Martini, 2010; Stern, 2011) are rare, although this complementarity exists in theoretical considerations and has been confirmed to some extent by empirical studies (Apostolakis, 1990; Arnberg and Bjorner, 2007; Koetse et al., 2008; Costantini and Paglialunga, 2014). In this paper, we consider a model in which, in contrast to most of the literature, complementarity between physical capital and natural resources is assumed. This complementarity exists primarily because non-renewable natural resources are the world's main source of energy. 
The purpose of this paper is to propose a model that depicts the described mechanism. The main aspect distinguishing this model from similar models is the assumption of complementarity between physical capital and energy. The model will be solved and analysed in detail. Conclusions for economic policy will also be drawn.

Previous literature on this subject has focused on empirical works associated with the estimation of willingness to pay (WTP) for renewable energy (among others, Wiser, 2007; Zografakis et al., 2010; Scarpa and Willis, 2010; Longo et al., 2008). An overview of this type of research is given in Stigka et al. (2014). These works were based on surveying residents of a given area to estimate their willingness to pay certain amounts in the form of taxes or voluntary donations (with or without additional government subsidies) in order to create an infrastructure that enables the production and distribution of energy from renewable sources. While these estimates may have provided some information on residents' preferences, there is a lack of theoretical research aimed at creating a model describing the decision-making process of households. The present work is also intended to fill this gap in the literature.

The novelty and contribution of the proposed model is as follows. First, we present a simple model of decision-making that illustrates the relationship between ecological and consumption preferences of households and their acceptance of government spending aimed towards achieving renewable energy production and distribution. This allows several conclusions to be drawn for economic policy directed to switch from non-renewable to renewable energy sources. Second, in spite of a large part of the existing theoretical research concentrated on non-renewable resources, we do not assume substitutability between energy and physical capital but complementarity between these two factors. A large stock of physical capital requires large amounts of energy, and does not, as in many models with the Cobb-Douglas production function, compensate small amounts of energy. Since the analysis conducted in this paper is not long-term and without technical progress, the assumption of complementarity is more correct and more consistent with economic intuition. to our best knowledge, this is the first theoretical model of its type that takes this complementarity into account. Third, since currently the energy is in a large part produced using non-renewable natural resources, the proposed model also takes this aspect into account, strengthening the conclusions for economic policy. Lastly, the proposed model considers the emissions of pollutants that negatively affect environmental quality and contribute to households' disutility. This concept is also worth emphasizing.

In the next section, we describe the construction of the proposed model. Then, in Section 3, we define, consider, and analyse the equilibrium state of the model. In Section 4, we analyse comparative statics of size of consumption due to changes in key parameters in the model, and Section 5 concludes the paper.

\section{Model}

We consider a static, one-period model of a closed economy that consists of two sectors. The government decides to begin using renewable sources for energy production. At the beginning of the analysed period, there is no infrastructure in the economy to produce 
such energy - there are no existing windmills, solar energy plants, no necessary transmission lines, etc. Therefore, some spending is required. On the one hand, this spending limits households' consumption, which affects utility negatively; on the other hand, however, it reduces emissions, which, in turn, affects utility positively. These two effects both have an influence on the total level of utility; however, which one prevails depends on the households' ecological preferences.

In the first sector - the production sector - physical capital $K$ and labour $L$ are used to produce an output. The production function is of the standard (Barro and Sala-i-Martin, 2003; Acemoglu, 2009) Cobb-Douglas form:

$$
Y=A K^{\alpha} L^{1-\alpha},
$$

where $A$ denotes the total factor productivity (TFP) and $\alpha \in(0 ; 1)$ and $1-\alpha \in(0 ; 1)$ are elasticities of the production with respect to physical capital and labour, respectively. for mathematical simplicity, we assume that $L \equiv 1$. Therefore, all variables in the model are considered per capita variables ${ }^{1}$.

The entire output produced in the economy is distributed between household consumption and expenditures, which have the purpose of creating the possibility to produce energy from renewable sources:

$$
Y=C+W_{E}
$$

In Equation 2, $C$ represents the level of consumption and $W_{E}$ denotes the size of the expenditures on energy production from renewable sources. Without any existing solar plants, windmills, etc., it is impossible to produce energy from renewable sources. to do this, it is necessary to spend a certain level of the output just to create basic possibilities. Obviously, $C=Y-W_{E}$, thus the consumption is equal to the size of the output that is not devoted to renewable energy expenditures.

Existing physical capital in the economy requires a certain level of energy. The demand for energy $E^{d}$ depends linearly on the level of $K$ in the economy:

$$
E^{d}=d K
$$

where $d$ is the energy efficiency parameter. One unit of physical capital requires exactly the level of energy equal to $d$. $d$ depends on the level of technology existing in the economy; whenever the technological level is higher, $d$ is expected to be lower.

The energy supply $E$ comes from two sources: non-renewable energy production $\left(E_{n}\right)$ and renewable energy production $\left(E_{0}\right)$ :

$$
E=E_{n}+E_{o} .
$$

Non-renewable energy is produced by burning a given amount of natural resources. We assume a linear relation between the amount of natural resources that are burnt and the level of the energy produced:

1 This approach is present in the standard literature; see, for example, Lucas (1987). 


$$
E_{n}=B \cdot R
$$

where $R$ is the flow of natural resources that are used in the energy production process, and $B$ is an energy production efficiency parameter. The burning of one unit of natural resources produces exactly $B$ units of energy. The parameter $B$ also depends on the technological level of the economy; with better accessible technology, more energy should be produced with the same amount of natural resources used. Alternatively, the same amount of energy can be produced with less natural resource use.

The burning of natural resources produces pollution:

$$
P=\eta \cdot R
$$

where $P$ is the stock of the pollution produced from the burning of a certain amount of natural resources $R$, and $\eta$ is a parameter of the burning technology cleanliness. With the use of one unit of natural resources, $\eta$ units of pollution are produced. $\eta$ also depends on the level of technology; $\eta$ can be expected to decline with the technological progress.

At the beginning, the economy has no infrastructure to produce energy from renewable sources; thus, this infrastructure is built with certain spending. Finally, the amount of energy produced from renewable sources in the considered economy depends on the level of spending $W_{E}$. We assume, for mathematical convenience, that this relationship is also linear:

$$
E_{0}=\delta \cdot W_{E},
$$

where $\delta$ is a parameter of the spending efficiency, which indicates how many units of energy are produced from one unit of spending on renewable energy production. The parameter $\delta$ is not only technological; it also has an institutional nature in that it depends on how efficiently public money is spent.

The economy maximizes the level of the household utility $U$, which is a function of the level of consumption and the level of pollution produced from burning natural resources:

$$
U(C, P) \rightarrow \max
$$

Consumption $C$ affects the level of utility positively, but with diminishing marginal utility (Acemoglu, 2009), while $P$ affects utility negatively. Therefore, we expect that $\frac{\partial U}{\partial C}>0$, $\frac{\partial^{2} U}{\partial C^{2}}<0$ and $\frac{\partial U}{\partial P}<0$

To choose the theoretically correct form of the utility function, the following questions should be answered:

1. Should utility be in a separable or non-separable form?

2. What should the sign of the second derivative $\frac{\partial^{2} U}{\partial P^{2}}$ should be? 
We assume not only the non-separable form of the utility function ${ }^{2}$ but also that other units of pollution bring more and more disutility than previous ones ${ }^{3}-\frac{\partial^{2} U}{\partial P^{2}}$. As a consequence, the utility function is of the following form ${ }^{4}$ :

$$
U(C, P)=C^{\theta}(X-P)^{\Omega}
$$

where $X$ denotes the utility from an environment in which there is no pollution, and $\theta$, $\Omega \in(0,1)$ are parameters of household preferences, which are equal to the elasticities of the utility with respect to the respective factor. In this case, households draw utility from consumption and from the state of the environment, while pollution harms the latter. We assume that $X-P \geq 0$, which means that the stock of the pollution cannot exceed the state of environmental quality. If this is the case, we assume that $X-P=0$, which implies that $U(C, P)=0$.

In sum, the economy maximizes the utility function, given by (9), with respect to conditions (1)-(7).

In the next section, we derive the solution to the model.

\section{Equilibrium Analysis}

In this section, we derive the solution to the proposed model. It is ineffective to produce more energy than needed, mostly due to the limited possibilities for storing energy produced (and unused). On the other hand, when there are existing possibilities of producing enough energy to satisfy the demand, it is efficient to do this. to sum this up, the effectiveness requires equality of energy demand and supply, which brings about the following equation:

$$
d K=B R+\delta W_{E} .
$$

This implies the following formula for the demand for natural resources:

$$
R=\frac{d}{B} K-\frac{\delta}{B} W_{E},
$$

which in turn entails the stock of the pollution:

$$
P=\frac{\eta d}{B} K-\frac{\eta \delta}{B} W_{E} .
$$

2 In light of a lack of clear empirical evidence of real-life household preferences, we decided to use a non-separable form of the utility function. With non-separable forms of the utility function, it is impossible to overcome the disutility caused by heavy pollution, no matter how high the consumption might be.

3 The positiveness of this derivative means that with additional units of pollution the decline in utility is lower (the function is convex with respect to $P$ ), households are willing to accept further units of pollution; thus, their sensitivity decreases in a more polluted environment. On the other hand, the negativeness of this derivative means that only the first few units of pollution are relatively easy to accept; however, when the environmental quality decreases, additional units of pollution bring more harm and more disutility to households, which seems to be theoretically accepted. See, for example, Grimaud and Rouge (2008). 
Household consumption is equal to the amount not spent on the renewable sources of the energy output:

$$
C=A K^{\alpha}-W_{E}
$$

Finally, the utility function is a one-variable function; thus, the only decision variable is $W_{E}$ :

$$
U\left(W_{E}\right)=\left(A K^{\alpha}-W_{E}\right)^{\theta}\left(X-\frac{\eta d}{B} K+\frac{\eta \delta}{B} W_{E}\right)^{\Omega} .
$$

The increase in $W_{E}$ has two opposing effects. On the one hand, it reduces the level of consumption. The model is static, and we therefore do not assume the possibility of saving and borrowing; thus, the entire output has to be distributed between $W_{E}$ and $C$. With an increase in $W_{E}$, the level of consumption must be lower. On the other hand, an increase in $W_{E}$ also increases the amount of energy produced from renewable sources, without the use of natural resources. This limits the stock of pollution and brings about an increase in utility that comes from environmental quality. The size of $W_{E}$ depends on the relative strength of both effects, which in turn depends on household preferences, reflected by the parameters $\theta$ and $\Omega$.

The optimal, utility-maximizing level of expenditures on renewable energy is given by:

$$
W_{E}=\frac{\delta \frac{\Omega}{\theta} A K^{\alpha}-\frac{B}{\eta} X+d K}{\delta+\delta \frac{\Omega}{\theta}} .
$$

This implies a formula for the size of the stock of non-renewable natural resources used in the energy production, which is as follows:

$$
R=\frac{d}{B} K-\frac{\delta \frac{\Omega}{\theta} A K^{\alpha}-\frac{B}{\eta} X+d K}{B+\frac{B \Omega}{\theta}} .
$$

By dividing both sides of Equation 15, we obtain the following formula for the share of output devoted to spending for the creation of possibilities of renewable energy production:

$$
w=1-c=\frac{W_{E}}{Y}=\frac{\delta \frac{\Omega}{\theta} A K^{\alpha}-\frac{B}{\eta} X+d K}{\delta A K^{\alpha}+\delta \frac{\Omega}{\theta} A K^{\alpha}}=1-\frac{\delta A K^{\alpha}+\frac{B}{\eta} X-d K}{\delta A K^{\alpha}+\delta \frac{\Omega}{\theta} A K^{\alpha}}>0 .
$$

In the next section, we analyse the solution obtained.

\section{Comparative Statics of the Optimal Size of Consumption}

In this section, we analyse the solution to our proposed model. The share of spendings on renewable energy depends on all the model parameters; therefore, we analyse the effects 
of changes in certain parameters. This is similar to the observed changes in two, identical economies, which differ only in the size of a single parameter. The signs of the derivatives in all cases are as follows:

$\frac{\partial w}{\partial \frac{\Omega}{\theta}}=\frac{\left(\delta A K^{\alpha}+\frac{B}{\eta} X-d K\right) \cdot \delta A K^{\alpha}}{\left(\delta A K^{\alpha}+\delta \frac{\Omega}{\theta} A K^{\alpha}\right)^{2}}>0-$ the size of the share of output devoted

to renewable energy spending does not depend on the size of the single preference parameters, but on the relation of these two parameters. Therefore, it is justifiable to calculate the derivative with respect to $\Omega / \theta$ rather than to single parameters. The sign of the derivative shows that if the relation of ecological preferences to consumption preferences is higher, then $w$ is higher. This effect seems quite obvious - with more "green" households, which draw more utility from environmental quality, it is possible to spend more on resource-saving technologies to produce more energy from renewable, non-polluting sources. However, $w$ does not change with an increase in $\Omega$ when the second preference parameter, $\theta$, also rises relatively, which results in the same level of $\Omega / \theta$. The conclusion for economic policy is that social campaigns aimed towards changing households' ecological preferences should include, at the same time, possible changes in consumption preferences to change the relation of both parameters to the desired one. Otherwise it may not be effective.

$\frac{\partial w}{\partial K}=\frac{(1-\alpha) d\left(\delta A K^{\alpha}+\delta \frac{\Omega}{\theta} A K^{\alpha}\right)}{\delta A K^{\alpha}+\delta \frac{\Omega}{\theta} A K^{\alpha}}>0-$ when we compare two economies that are and identical differ only in one parameter - the size of stock of physical capital - the one with the greater $K$ has a higher share of output devoted to spending on renewable energy. This is strictly connected to the fact that greater $K$, on the one hand, is connected to a greater output, which in turn implies more consumption. On the other hand, a greater $K$ requires more energy, which, in part, is produced using non-renewable natural resources and causes more pollution.

$\frac{\partial w}{\partial B}=-\frac{\frac{1}{\eta} X}{\delta A K^{\alpha}+\delta \frac{\Omega}{\theta} A K^{\alpha}}<0-$ when the effectiveness of energy production from nonrenewable sources is higher, the share of the output devoted to spendings on renewable energy is lower. This is quite an expected effect, as an economy that produces more energy from the same stock of non-renewable natural resources and, at the same time, produces the same amount of pollution, is naturally less inclined to spend more of the output (and reduce the current consumption) to create possibilities for producing energy using renewable sources. In these cases, $w$ is lower. 
$\frac{\partial w}{\partial \eta}=\frac{\frac{B}{\eta^{2}} X}{\delta A K^{\alpha}+\delta \frac{\Omega}{\theta} A K^{\alpha}}>0-$ the stock of pollution is one of the factors in the utility

function which reduce the total utility drawn from consumption. Therefore, when the use of one unit of a natural resource in energy production leads to higher pollutant emissions, the utility is lower; thus, the economy is more inclined to switch to using renewable energy sources. In this case, the economy will need to reduce its consumption for a while (so that $w$ is higher) to reduce the stock of pollution in the future and, at the same time, increase the level of total utility.

$\frac{\partial w}{\partial X}=-\frac{\frac{B}{\eta}}{\delta A K^{\alpha}+\delta \frac{\Omega}{\theta} A K^{\alpha}}<0-$ if the environmental quality is lower, the share of spending on renewable energy is higher. With lower $X$, the disutility connected to one unit of pollution is higher and more perceptible by households; thus, the households are more interested in limiting the stock of pollution. The higher share of output devoted to renewable energy certainly does this.

$\frac{\partial w}{\partial d}=\frac{K}{\delta A K^{\alpha}+\delta \frac{\Omega}{\theta} A K^{\alpha}}>0-$ the demand for energy is the main variable that forces an economy to use natural resources and, thus, emit pollution. In our model, this demand comes from the use of physical capital, but depends on two factors: the stock of the physical capital and the level of energy efficiency. The latter is strictly connected to the generation of physical capital withitstechnological advancement; lesstechnologically advanced types of physical capital require more energy. In a comparison of two identical economies that differ only in the size of $d$ (energy efficiency parameter), the one with the older type of physical capital (with greater $d$ ) requires more energy. Thus, when the demand for energy is satisfied only with energy produced from non-renewable, polluting sources, then in that economy, the production of pollution is higher, which implies a lower level of utility even if the output (and consumption) is exactly the same. In this case, the economy with the higher $d$ is willing to spend a greater share of its output on renewable energy production.

The signs of the other derivatives $\left(\frac{\partial w}{\partial \delta}, \frac{\partial w}{\partial A}, \frac{\partial w}{\partial \alpha}\right)$ depend on the sign of the expression $X-\frac{\eta}{B} d K$, which can be interpreted as the actual state of the environment minus the stock of pollution generated in a situation where the entire demand for energy is satisfied with nonrenewable, polluting sources. When $K<\frac{B}{d \eta} X\left(X-\frac{\eta}{B} d K>0\right)$, then $\frac{\partial w}{\partial \delta}, \frac{\partial w}{\partial A}, \frac{\partial w}{\partial \alpha}>0$. 
In relatively poor economies (with lower $K$ ), an increase in TFP or in the elasticity of the output with respect to physical capital or an increase in the effectiveness of spending on renewable energy leads to greater social acceptance of spending on renewable energy. This is probably true for most of the modern economies.

If $K>\frac{B}{d \eta} X\left(X-\frac{\eta}{B} d K<0\right)$, then $\frac{\partial w}{\partial \delta}, \frac{\partial w}{\partial A}, \frac{\partial w}{\partial \alpha}<0$. In relatively rich economies (with greater $K$ ), an increase in $A, \alpha$ and $\delta$ is connected with a decrease in the propensity of households to renewable energy spending, which has not been empirically observed in any current economies. Therefore, we can conclude that the former case reflects the current world situation.

The interpretation of a case in which $W_{E} \leq 0$ is that there is no social acceptance for any public spending on renewable energy sources. This is not only a result of the value of the preference parameters (both ecological and consumption preferences), but also of technological parameters (such as $d$ and $B$ ) and the state of the economy (e.g., the stock of $K$ ). In this case, public spending on renewable energy sources needs to be equal to zero, unless:

- the relation of households' ecological preferences to their consumption preferences changes, becoming more convenient;

- more physical capital is accumulated, which implies a greater demand for energy and a greater amount of pollutants emitted;

- technological progress increases the level of the output produced, which raises the level of consumption, which in turn, by diminishing marginal utility, leads to a greater propensity to spend on renewable energy sources;

- the state of the environment becomes more severe for households.

A similar analysis can be made for the amount of natural resources used in the production of energy $R$. The respective derivatives for this variable are similar (as is directly apparent from the comparison between Equations 15 and 16. Factors that affect $w$ positively also affect $R$ negatively. In particular $5, \frac{\partial R}{\partial \frac{\Omega}{\theta}}<0$. Thus, a positive change in the relation of ecological preferences to consumption preferences has a negative influence on the amount of natural resources used in the energy production process, which, of course, also delays the longterm depletion of non-renewable natural resources. Equation 6 also implies a decrease in the amount of pollutants emitted in this case, which in turn implies higher environmental quality and an increase in utility. These results are consistent with theory and economic intuition.

$5 \quad$ Simple calculations are left to the reader. 


\section{Conclusions}

Governments decide on their renewable energy expenditures by taking into account the ecological preferences of society. This comes as no surprise - otherwise during the next election, the government would be changed to one that better serves the interests of the nation. However, it is important to note that the ecological preferences of residents in different countries are different. Different responses exist regarding the current levels of environmental pollution in Western Europe, Asia, Africa or North America. Ecological preferences strongly influence the expenditures that a state budget can incur for renewable energy. This is the classic problem of economic interchangeability - spending reduces consumption, which reduces the level of utility; on the other hand, however, replacing non-renewable energy sources with renewable ones decreases the level of pollutants emitted. This in turn leads to a decrease in disutility, which implies an increase in the level of total utility. These two effects, acting in opposite directions, are equalized by comparing the marginal utility.

In this paper, we present and analyse a simple macroeconomic model with optimization, which aims to present the described dependence. The model describes a two-sector economy in which manufacturing of goods and services and energy production occur. Energy is needed in this modelled economy to power the existing physical capital that is used in the first sector. Energy is produced by burning existing natural resources, which in turn produces pollutants. However, there exists the opportunity to create an infrastructure that enables the generation of energy from renewable sources. for these purposes, it is necessary to reduce the consumption. The decision on how much of its income the economy is able to contribute is determined by maximizing the households' utility function, which depends on the level of consumption and the amount of pollutants emitted. Parameters of the utility function determine the marginal utility of the change in each factor per unit.

An analysis of this simple model leads to the conclusion that maximizing the utility share of the total production that is spent on renewable energy generation depends not on the individual preference parameter - particularly the ecological preference parameter - but on the relations of both preference parameters. This fact offers several interesting conclusions for economic policy. If it is in the interest of the government to switch the economy to using only renewable energy sources, then obviously, there should be as much spending as possible on creating the right infrastructure. In order to do this, it is important to influence households' preferences to gain public approval to using the highest possible share of renewable energy expenditures in the total production. to influence households' preferences, the government may, through various social campaigns, promote certain attitudes, informing and convincing to austerity. However, these campaigns should not affect single preference parameters, such as those related to pollutants, but also the others, to ensure that the relationship of both parameters together changes to a desirable one. If a campaign is aimed only at a single parameter, there is no guarantee that other factors will simultaneously not affect the preference relationship. That would ultimately result in a negative effect. 
It should be noted that the analysed model is constructed under the assumption of complementarity between physical capital and energy, which seems to be more in line with observed reality than the more common assumption of substitutability between these two variables. The results, however, are still consistent with theory and economic intuition, which allows us to believe that the proposed model reflects reality.

The presented model, although it does help to explain some economic mechanisms, may become part of a larger model for, for example, determining the optimal moment for a transition to renewable energy. This issue has already been discussed in detail in the literature, although the existing models are quite mathematically complex.

\section{References}

Acemoglu, D. (2009). Introduction to Modern Economic Growth. Cambridge, Massachusetts, USA: Princeton University Press. ISBN 9780691132921.

Amigues, J. P., Grimaud, A., Moreaux, M. (2004). Optimal Endogenous Sustainability with an Exhaustible Resource through Dedicated R\&D. Les Cahiers du LERNA, 4, 154 .

Apostolakis, B. E. (1990). Energy-capital Substitutability/Complementarity: The Dichotomy. Energy Economics, 12(1), 48-58, https://doi.org/10.1016/0140-9883(90)90007-3

Arnberg, S., Bjorner, T. B. (2007). Substitution between Energy, Capital and Labour within Industrial Companies: A micro Panel Data Analysis. Resource and Energy Economics, 29(2), 122-136, https://doi.org/10.1016/j.reseneeco.2006.01.001

Barro, R. J., Sala-i-Martin, X. (2003). Economic Growth. 2nd. Cambridge, Massachusetts, USA: MIT Press. ISBN 9780262025539.

Burke, P. J. (2010). Income, Resources, and Electricity Mix. Energy Economics, 32(3), 616-626, https://doi.org/10.1016/j.eneco.2010.01.012

Costantini, V., Martini, C. (2010). The Causality between Energy Consumption and Economic Growth: A Multi-sectoral Analysis Using Non-stationary Cointegrated Panel Data. Energy Economics, 32(3), 591-603, https://doi.org/10.1016/j.eneco.2009.09.013

Costantini, V., Paglialunga, E. (2014). Elasticity of Substitution in Capital-energy Relationships: How Central is a Sector-based Panel Estimation Approach? Sustainability Environmental Economics and Dynamics Studies. Working Paper No. 1314.

Costanza, R., Daly, H. E. (1992). Natural Capital and Sustainable Development. Conservation Biology, 6(1), 37-46, https://doi.org/10.1046/j.1523-1739.1992.610037.x

da Silva, A. S. (2008). Growth with Exhaustible Resource and Endogenous Extraction Rate. Economic Modelling, 25(6), 1165-1174, https://doi.org/10.1016/j.econmod.2008.03.001

Dasgupta, P., Heal, G. (1974). The Optimal Depletion of Exhaustible Resources. The Review of Economic Studies, 41(5), 3-28, https://doi.org/10.2307/2296369

Di Vita, G. (2006). Natural Resources Dynamics: Exhaustible and Renewable Resources, and the Rate of Technical Substitution. Resources Policy, 31(3), 172-182, https://doi.org/10.1016/j. resourpol.2007.01.003

Georgescu-Roegen, N. (1979). Energy Analysis and Economic Valuation. Southern Economic Journal, 45(4),1023-1058, https://doi.org/10.2307/1056953

Greiner, A. (2005). Fiscal Policy in an Endogenous Growth Model with Public Capital and Pollution. The Japanese Economic Review, 56(1), 67-84, https://doi. org/10.1111/j.1468-5876.2005.00299.x 
Grimaud, A., Roug e, L. (2003). Non-renewable Resources and Growth with Vertical Innovations: Optimum, Equilibrium and Economic Policies. Journal of Environmental Economics and Management, 45(2), 433-453, https://doi.org/10.1016/s0095-0696(02)00049-9

Grimaud, A., Roug e, L. (2005). Polluting Non-renewable Resources, Innovation and Growth: Welfare and Environmental Policy. Resource and Energy Economics, 27(2), 109-129, https://doi.org/10.1016/j.reseneeco.2004.06.004

Grimaud, A., Roug e, L. (2008). Environment, Directed Technical Change and Economic Policy. Environmental and Resource Economics, 41(4), 439-463, https://doi.org/10.1007/ s10640-008-9201-4

Grimaud, A., Roug e, L. (2014). Carbon Sequestration, Economic Policies and Growth. Resource and Energy Economics, 36(2), 307-331, https://doi.org/10.1016/j.reseneeco.2013.12.004

Koetse, M. J., De Groot, H. L., Florax, R. J. (2008). Capital-energy Substitution and Shifts in Factor Demand: A Meta-analysis. Energy Economics, 30(5), 2236-2251, https://doi.org/10.1016/j. eneco.2007.06.006

Lin, C. Y. C., Meng, H., Ngai, T. Y., Oscherov, V., Zhu, Y. H. (2009). Hotelling Revisited: Oil Prices and Endogenous Technological Progress. Natural Resources Research, 18(1), 29-38, https://doi.org/10.1007/s11053-008-9086-5

Longo, A., Markandya, A., Petrucci, M. (2008). The Internalization of Externalities in the Production of Electricity: Willingness to Pay for the Attributes of a Policy for Renewable Energy. Ecological Economics, 67(1), 140-152, https://doi.org/10.1016/j. ecolecon.2007.12.006

Lucas, R. E. (1988). On the Mechanics of Economic Development. Journal of Monetary Economics, 22(1), 3-42, https://doi.org/10.1016/0304-3932(88)90168-7

Maeda, A., Nagaya, M. (2012). The Optimal Timing of the Transition to New Environmental Technology for Economic Growth. Modern Economy, 3(3), 263-274, https://doi. org/10.4236/me.2012.33036

Mosiño, A. (2012). Producing Energy in a Stochastic Environment: Switching from Non-Renewable to Renewable Resources. Resource and Energy Economics, 34(4), 413-430, https://doi.org/10.1016/j.reseneeco.2012.04.002

Neustroev, D. (2013). The Uzawa-Lucas Growth Model with Natural Resources. University Library of Munich, Germany. Working Paper No. 52937.

Pautrel, X. (2008). Reconsidering the Impact of the Environment on Long-run Growth when Pollution Influences Health and Agents have a Finite-lifetime. Environmental and Resource Economics, 40(1), 37-52, https://doi.org/10.1007/s10640-007-9139-y

Pautrel, X. (2009). Pollution and Life Expectancy: How Environmental Policy can Promote Growth. Ecological Economics, 68(4), 1040-1051, https://doi.org/10.1016/j. ecolecon.2008.07.011

Pittel, K., Bretschger, L. (2010). The Implications of Heterogeneous Resource Intensities on Technical Change and Growth. Canadian Journal of Economics/Revue canadienne d'Ă@conomique, 43(4), 1173-1197, https://doi.org/10.1111/j.1540-5982.2010.01610.x

Scarpa, R., Willis, K. (2010). Willingness-to-pay for Renewable Energy: Primary and Discretionary Choice of British Households' for Micro-generation Technologies. Energy Economics, 32(1), 129-136, https://doi.org/10.1016/j.eneco.2009.06.004

Scholz, C. M., Ziemes, G. (1999). Exhaustible Resources, Monopolistic Competition, and Endogenous Growth. Environmental and Resource Economics, 13(2), 169-185. 
Schou, P. (2002). When Environmental Policy is Superfluous: Growth and Polluting Resources. The Scandinavian Journal of Economics, 104(4), 605-620, https://doi. org/10.1111/1467-9442.00304

Smulders, S., De Nooij, M. (2003). The Impact of Energy Conservation on Technology and Economic Growth. Resource and Energy Economics, 25(1), 59-79, https://doi.org/10.1016/ s0928-7655(02)00017-9

Solow, R. M. (1974). Intergenerational Equity and Exhaustible Resources. The Review of Economic Studies, 41(5), 29-45, https://doi.org/10.2307/2296370

Stern, D. I., Cleveland, C. J. (2004). Energy and Economic Growth. Encyclopedia of Energy, 2, $35-51$.

Stern, D. I. (2011). The Role of Energy in Economic Growth. Annals of the New York Academy of Sciences, 1219(1), 26-51, https://doi.org/10.1111/j.1749-6632.2010.05921.x

Stigka, E. K., Paravantis, J. A., Mihalakakou, G. K. (2014). Social Acceptance of Renewable Energy Sources: A Review of Contingent Valuation Applications. Renewable and Sustainable Energy Reviews, 32, 100-106, https://doi.org/10.1016/j.rser.2013.12.026

Stiglitz, J. (1974). Growth with Exhaustible Natural Resources: Efficient and Optimal Growth Paths. Review of Economic Studies, 41(5), 123-137, https://doi.org/10.2307/2296377

Stuermer, M., Schwerhoff, G. (2013). Technological Change in Resource Extraction and Endogenous Growth. Bonn Econ. Discussion Papers No. 12, https://doi.org/10.2139/ ssrn.2364046

Tahvonen, O., Salo, S. (2001). Economic Growth and Transitions between Renewable and Nonrenewable Energy Resources. European Economic Review, 45(8), 1379-1398, https:// doi.org/10.1016/s0014-2921(00)00062-3

Van Zon, A., Yetkiner, I. H. (2003). An Endogenous Growth Model with Embodied Energy-Saving Technical Change. Resource and Energy Economics, 25(1), 81-103, https://doi.org/10.1016/ s0928-7655(02)00018-0

Wiser, R. H. (2007). Using Contingent Valuation to Explore Willingness to pay for Renewable Energy: A Comparison of Collective and Voluntary Payment Vehicles. Ecological Economics, 62(3-4), 419-432, https://doi.org/10.1016/j.ecolecon.2006.07.003

Xepapadeas, A. (2005). Economic Growth and the Environment. Handbook of Environmental Economics, 3, 1219-1271, https://doi.org/10.1016/s1574-0099(05)03023-8

Zografakis, N., Sifaki, E., Pagalou, M., Nikitaki, G., Psarakis, V., Tsagarakis, K. P. (2010). Assessment of Public Acceptance and Willingness to Pay for Renewable Energy Sources in Crete. Renewable and Sustainable Energy Reviews, 14(3), 1088-1095, https://doi.org/10.1016/j. rser.2009.11.009 